\title{
Educación ambiental crítica en la República de Panamá
}

El artículo tiene por principal objetivo describir la Educación Ambiental (EA) en la República de Panamá (Panamá). En referencias bibliográficas ofrecidas y fundamentadas de una EA crítica posterior a cursar y concluir las disciplinas de Ética, Principios de Educación Ambiental y de Comprender la Legislación Ambiental, en el Programa de Post Graduación en Educación Ambiental (PPGEA), en la Universidad Federal do Rio Grande - FURG, Brasil. Disciplinas que aportan fundamentos, referencias bibliográficas y aportan análisis en respecto a una EA crítica. Cuya importancia en este artículo parte de conocer el contexto cronológico de la EA a nivel mundial y la vinculación a los inicios propios de la EA en Panamá. Tomando en consideración los aspectos en la cual se presentaba la sociedad panameña, ya sea cultural, política, social. También analizando lo respecto al marco legal de EA de Panamá, en la cual está presente la estructura panameñas al referirse a lo ambiente y a la EA, en sus constantes fundamentos y apoyo al desarrollo de la sociedad. Dando importancia y un análisis a las dos legislaciones de EA presentes en Panamá y a las debidas entidades gubernamentales, en las cuales la EA toma notoriedad y propuestas, siempre en una base de una EA critica que pueda contribuir a una mejor sociedad.

Palavras-chave: Educación Ambiental; República de Panamá; Educación Ambiental Crítica.

\section{Educação ambiental crítica na República do Panamá}

O principal objetivo do artigo é descrever a Educação Ambiental (EA) na República do Panamá (Panamá). Em referências bibliográficas oferecidas e apoiadas por uma AE crítica, após estudar e concluir as disciplinas de Ética, Princípios de Educação Ambiental e Entendimento da Legislação Ambiental, no Programa de PósGraduação em Educação Ambiental (PPGEA), da Universidade Federal do Rio Grande - FURG, Brasil. Disciplinas que fornecem fundamentos, referências bibliográficas e fornecem análises sobre um EA crítico. A importância deste artigo começa com o conhecimento do contexto cronológico da DA em todo o mundo e o link para o início da DA no Panamá. Levando em consideração os aspectos em que a sociedade panamenha se apresentou, seja cultural, política ou social. Analisando também o que está relacionado ao arcabouço jurídico da AA do Panamá, em que a estrutura panamenha está presente quando se refere ao meio ambiente e à EA, em seus constantes fundamentos e apoio ao desenvolvimento da sociedade. Dar importância e uma análise às duas legislações da EA presentes no Panamá e às devidas entidades governamentais, nas quais a EA recebe notoriedade e propostas, sempre com base em uma EA crítica que possa contribuir para uma sociedade melhor.

Palavras-chave Educação ambiental; República do Panamá; Educação Ambiental Crítica.

Topic: Educação Ambiental

Reviewed anonymously in the process of blind peer.
Received: 19/03/2020

Approved: $20 / 04 / 2020$

Lenin Alfonso Morales (iD)

Universidade Federal do Rio Grande, Brasil http://lattes.cnpq.br/6526060505118483

http://orcid.org/0000-0003-0071-1956

moralesla28@gmail.com

Vanessa Hernandez Caporlingua (id

Universidade Federal do Rio Grande, Brasil

http://lattes.cnpq.br/4343042937109951

http://orcid.org/0000-0002-8617-1892

vcaporlingua@gmail.com 


\section{INTRODUCCIÓN}

Este artículo tiene como objetivo principal enfatizar la EA desde sus inicios en Panamá, conectado al origen y a las actividades de la EA a nivel mundial, ligado a los diversos acontecimientos de la sociedad panameña hasta tiempo actuales, reflejados en diversos contextos sociales, culturales, políticos. Como justifica a este artículo se presenta la necesidad de poder brindar una documentación al campo de la EA de Panamá, que hoy presenta el déficit de investigaciones, así como su presencia en solo dos legislaciones de EA que rige la sociedad panameña.

El artículo está dividido en una secuencia presentando la metodología seleccionada, posterior aborda la cronología de la EA y sus antecedentes en el país centroamericano. Con culminación en un análisis de la concepción de la EA en la República de Panamá a través de sus legislaciones ambientales establecidas, su marco legal y las diversas estructuras gubernamentales. Para concluir con la importancia de la EA crítica en el gobierno y la sociedad panameña ante la realidad presente en la temática ambiental y de la EA.

\section{METOdOLOGÍA}

Esta investigación tiene como fundamento metodológico de ser de aspecto cualitativo de pesquisa teórica bibliográfica y documentada. De esta metodología aporta Sato (2001) que se utiliza para consolidar los conocimientos, a través de la bibliografía ya publicada de pensamientos y personalidades, así como documentos que contienen hechos históricos para ser investigados, en esta investigación recayendo en cada lectura ofrecida por los cursos y analizando lo proporcionado en las legislaciones de EA de Panamá y sus diversas entidades gubernamentales.

Esta metodología, en base a la recolecta en primera instancia de las referencias bibliográficas que aporten la EA tanto a nivel internacional, como a nivel nacional de Panamá. Con el fin de poder conocer el surgimiento y un posicionamiento a los diversos acontecimientos a nivel mundial. Para posterior analizar el comimenzo de la EA en Panamá.

Esta metodología irá en dialogo, direccionado y fundamentado del análisis de los contenidos y materiales ofrecidos por las disciplinas de Ética, Principios de Educación Ambiental y de Comprender la Legislación Ambiental, cursadas en el Programa de Post Graduación en Educación Ambiental (PPGEA), en la Universidad Federal do Rio Grande - FURG, Brasil. Con el objetivo de poder realizar un dialogo de la importancia de EA crítica en este país centroamericano.

Posterior se hace énfasis en el marco legal, tácitamente en el estudio de las legislaciones de EA de Panamá, así como sus estructuras gubernamentales. Para consolidar como resultado de esta investigación un aporte a tener documentación de EA en Panamá, que hoy presenta un carecimiento y que nos proporcione una relación de la EA crítica con las percepciones de la EA de Panamá y su estructura gubernamental., donde la EA crítica pueda ser una posibilidad de transformación. 


\section{Un poco de la historia del surgimento de la educacion ambiental}

Hablar de Educación Ambiental (EA) en contexto general y en referencias documentadas bibliográficas, es trasladarnos mentalmente a la década de los 60 , donde su mención como concepto es relacionada a una problemática en respecto a la degradación de recursos naturales y por el consumo que presentaba la población (REIGOTA, 2006). Aporta Loureiro (2012) que en términos cronológicos la EA se adoptó como concepto en un evento de educación promovida por la Universidad de Keele, en el Reino Unido, en 1965. En esa misma línea de acontecimientos aporta (LOUREIRO, 2012) que es en la Conferencia de las Naciones Unidas sobre el Ambiente Humano en Estocolmo, realizado del 5 a 16 de junio de 1972, donde se atienta la necesidad de criterios, de principios comunes que den a los pueblos del mundo, la inspiración y guía para preservar y mejorar el medio ambiente humano. En una definición y posicionamiento antropocéntrico, donde el documento al describir al ser humano como importante en la sociedad y su responsabilidad de la siguiente manera "o homem" é ao mesmo tempo obra e construtor do meio ambiente que o cerca, o qual the dá sustento material e the oferece oportunidade para desenvolver-se intelectual, moral, social e espiritualmente" (ONU, 1972). También destaca que "a proteção e o melhoramento do meio ambiente humano é uma questão fundamental que afeta o bem-estar dos povos e o desenvolvimento econômico do mundo inteiro, um desejo urgente dos povos de todo o mundo e um dever de todos os governos" (ONU, 1972). Entre los principales principios, se destaca el siguiente principio:

O princípio de que o ser humano tem direito à liberdade, à igualdade e a uma vida com condições adequadas de sobrevivência, num meio ambiente que the permita usufruir de uma vida digna, consagrou-se como um marco no que se refere à regulação jurídicointernacional de proteção ambiental. (VASCONCELOS, 2012).

De este principio donde se menciona el derecho a la libertad e igualdad en un ambiente con una vida digna, en conjunto a las posteriores conferencias mencionados en la cronología de la EA, se destaca entre ellos el Congreso de Belgrado (1975) y la Conferencia Intergubernamental de Educación Ambiental de Tiblisi (1977), donde fueron previstos los principios de Educación Ambiental en los documentos finales de la Conferencia Intergubernamental, los cuales resultaron de prolongamientos ya existentes en la Conferencia de Estocolmo y del Congreso de Belgrado (CAPORLINGUA, 2010).

Cada congreso internacional nos va dando una amplitud y seguimiento de la importancia de la EA, de Tiblisi (1977); es importante tener presente que es donde se establece diversos principios, entre las cuales hoy en día el principio de participación y solidaridad toma una importancia para poder establecer un entendimiento de los diversos problemas y conflictos ambientales. Destaca Caporlingua (2010) que el principio de la participación o solidaridad persigue la actuación y participación de la sociedad al adoptar comportamientos de protección al medio ambiente.

Con la participación de diversos países a nivel mundial a través de la realización de más conferencias, van mostrando la preocupación del ser humano y su relación con su ambiente, posterior se realiza en Rio de Janeiro (1992), la conferencia conocida como Eco 92, conocido con el documento y redactado bajo el nombre

\footnotetext{
${ }^{1}$ El término utilizado es el hombre, por ser traducción directa del documento, sin embargo, entendiendo en el campo de EA hoy en día como ser humano.
} 
de Tratado de Educación Ambiental para sociedades sustentables y responsabilidad global, donde el tratado describe la educación como:

Um processo dinâmico em permanente construção. Deve, portanto, propiciar a reflexão, o debate e a sua própria modificação. Nós signatários, pessoas de todas as partes do mundo, comprometidos com a proteção da vida na Terra, reconhecemos o papel central da educação na formação de valores e na ação social. Nos comprometemos com o processo educativo transformador através do envolvimento pessoal, de nossas comunidades e nações para criar sociedades sustentáveis e equitativas (ONU, 1992).

De Rio 92, importante resaltar que en la historia es la mayor reunión con fines pacíficos realizada en la historia humana, contando con la presencia de 180 jefes de Estado e la participación, literalmente, de todos los países del mundo (GRÜN, 2006). Destaca Dias (1992) que en Rio 92, se atribuyen los esfuerzos para la búsqueda de la mejoría de la calidad ambiental, teniendo la EA como protagonista en búsqueda de respuesta a una problemática planteada por los diversos países participantes en su respectivo momento. Rio 92 marca el avance de las diversas naciones en el plantear y la preocupación de un mejor entendimiento entre el ser humano y el ambiente, y un enlace a la historia de la EA y al ambientalismo. Entendiendo este término como "um ideário e identidade de grupos, redes e movimentos sociais de múltiplas orientações político-ideológicas, tendo como eixo comum a discussão acerca da relação sociedade-natureza" (LOUREIRO, 2012).

El entender o la búsqueda de la comprensión de la EA en la actualidad, no solo es asociar su importancia a conferencias a nivel mundial, sino en una reflexión a los acontecimientos históricos, donde diversas sociedades han estado presentes y causados las diversas problemáticas actuales ambientales, que hoy proponen una reflexión y critica a los acontecimientos que propusieron que sea tan importante, Grün (2006) apunta que:

Em julho de 1945, no Deserto de Los Alamos, Novo México, Estados Unidos, o azul do céu transformou- se subitamente em um clarão ofuscante pela explosão da primeira bomba $\mathrm{H}$. que depois eram jogadas como bombas atômicas sobre as populações civis de Hiroshima e Nagasaki, onde os seres humanos adquirem autoconsciência da possibilidade de destruição total completa do planeta. Em 1962, Rachel Carson publica seu antológico Silent Spring, onde leva a público o problema dos pesticidas na agricultura e mostra o desaparecimento das espécies, tornando se um clássico do ambientalismo.

Así, por consiguiente, al hablar de EA, es poder tener presente que las diversas documentaciones de EA, tiene su origen en problemáticas y conflictos ambientales, en el cual el ser humano a través de sus decisiones ha incidido sobre el medio ambiente y sobre otras culturas. Ante esta realidad es que nos inserimos en una crisis socioambiental, es decir en una relación de la dimensión natura y social. Reflejado en los diversos acontecimientos a nivel mundial, donde las actividades del ser humano han incidido ya sea la deforestación, mudanzas ambientales, entre otros. Es decir, que los inicios de la EA son relacionados a los diversos desastres ocasionados por diversas naciones a nivel mundial.

\section{DISCUSIÓN TEÓRICA}

\section{Educación ambiental en la República de Panamá}

Para analizar la EA en Panamá, es necesario primeramente conocer el contexto histórico de Panamá 
y sus acontecimientos que han dado paso a la sociedad actual, que conlleva a las diversas estructuras del gobierno panameño en referencia ambientales y de la EA.

El país centroamericano se separa de Colombia el 3 de noviembre de 1903, con el acontecimiento de la construcción del Canal de Panamá por los Estados Unidos, obra que dio inicios con los franceses años anteriores, que terminó con el fracaso de la obra debido a planificaciones erradas. Esta construcción se dio con la culminación por parte de los Estados Unidos de Norteamérica, para posterior en el año de 1999 regresar a manos panameñas.

En su vida Republicana de 1903 hasta tiempos actuales, Panamá va atravesando diversos acontecimientos, entre los más destacados en campos sociales y políticos que influencian en el medio ambiente:

Panamá cambió en temas sociales, políticos de forma extraordinaria, en ese período, el ejército de Estados Unidos invadió la ciudad de Panamá (1989), cayó el régimen militar (1968-1989), se recuperó el Canal (31-12-1999), la población se incrementó de 1.5 millón de personas a 4,0 millones de habitantes (2019), y el desarrollo estructural y económico aumentó. (LA PRENSA, 2013).

De estos acontecimientos que marcan la vida república de Panamá, se da a reflexionar que en la década de 60, cuando es el surgimiento y comienzo de la EA en sentido de conferencias y documentaciones. Panamá pasaba por una dictadura militar, en cuanto la EA enfatizaba su preocupación ambiental a nivel mundial, oficializado en documentos ratificados, a través de reuniones internacionales, nacionales, regionales. Estos acontecimientos internacionales sobre EA, refleja y hace repercusión en Panamá, sin embargo en un posicionamiento de que el país no se consideraba o no se encontraba entre los países que por su nivel de desarrollo provocaban efectos negativos al medio ambiente (PANAMÁ, 2017).

Panamá propone poner en práctica lo descrito y aprobado en los diversos documentos, pero en un punto de partida de que los países más contaminantes deberían procurar medidas más amigables y menos contaminantes al medio ambiente. Sin embargo, debemos hoy considerar que uno de los desafíos modernos, es aprender a vivir juntos en nuestra tierra y ciertamente el desafío ético y político más exigente fundamental de nuestra sociedades (SAUVÉ, 2016). Aun en ese posicionamiento de no ser un contaminante en grandes extensiones, Panamá advierte la necesidad de sumarse a los esfuerzos internacionales, para coadyuvar en su sostenimiento y con iniciativas para la preservación del ambiente, a través de la firma y posterior ratificación de convenciones y protocolos internacionales ambientales (PANAMÁ, 2017).

En Panamá la EA tiene sus orígenes a finales de la década de los 60 e inicios de los 70, en un sentimiento patriótico y relacionado con profundidad con la recuperación de la soberanía en el territorio nacional y del Canal de Panamá (DIAZ-PINZÓN, 2013). Canal de Panamá que estaba en manos de los Estados Unidos hasta el año de 1999, por la cual el pueblo panameño realizo muchos esfuerzos para su recuperación, que ocasiono grandes disturbios por los diversos enfrentamientos diarios entre la fuerza estadounidense y el pueblo panameño. Considerando que concorde a estos acontecimientos, a nivel mundial se va tomando conciencia en el tema ambiental en el siglo XX.

Panamá toma acción y a partir de la década de 1970 promueve la creación de las estructuras requeridas para implementar las normativas ambientales vigentes, recayó en la Dirección de Recursos 
Naturales Renovables (RENARE) del Ministerio de Desarrollo Agropecuario, creado por la Ley 12 de 1973, posterior mediante la Ley 21 de 1986 como el Instituto Nacional de Recursos Naturales Renovables (INRENARE), ente adscrito al Ministerio de Economía y Finanzas, después en la Autoridad Nacional de Ambiente (ANAM), mediante la Ley 41 de 1998, luego el Ministerio de Ambiente (MIAMBIENTE), mediante la Ley 8 de 2015 (PANAMÁ, 2017).

\section{Marco legal de la educación ambiental en Panamá}

Panamá presenta su primera legislación de EA en 1992, conocida como Ley no 10 de Educación Ambiental (1992), publicado en La Gaceta no 22068 del 1 de julio de 1992. Esta Ley establece el siguiente enunciado "Por la cual se adopta la educación ambiental como una estrategia nacional para conservar y desarrollar los recursos naturales y preservar el ambiente, y se dictan otras disposiciones" (PANAMÁ, 1992). De este enunciado los conceptos de conservación y desarrollo de recursos naturales nos proporcionan una clara perspectiva conservacionista de la EA. Perspectiva que se relaciona a una corriente de conservar, de naturalista, de una EA verde, entre la cual también se puede mencionar el ecoturismo, senderismo, biodiversidad, unidad de conservación, biomas específicos (LAYRARGUES, 2014).

\section{Ley № 10 del 1 de julio de 1992}

La Ley $n^{\circ} 10$, primera legislación de EA en Panamá y en la cual se adopta la EA como una estrategia nacional para conservar y desarrollar los recursos naturales y preservar el ambiente. Aporta Franco (2015) que debe incluir el contenido del enfoque ambiental en los programas de estudio de las escuelas e incluso en las universidades. Sin embargo, en cuanto a la Educación Ambiental formal, aquella realizada en las aulas de clases, recae esta competencia del Ministerio de Educación, MEDUCA, se hace muy poco.

En el Artículo 2 que "el Estado promoverá, apoyará y facilitará la Integración de la educación relativa a los recursos naturales y el ambiente por medio de las funciones de educación, capacitación, extensión o Investigación" (PANAMÁ, 1992). En un análisis del artículo 2, nos propone la EA como parte de una relación del ser humano con los recursos naturales y en la cual esta disposición recae en el estado las diversas funciones, incluyendo en los programas de estudio de los colegios primarios y secundarios, incluso la educación superior del país, descrito de la siguiente manera en el Artículo 3 “Inclúyase el contenido y enfoque ambiental en los programas de estudio de las escuelas y colegios del nivel inicial, primario, medio y en los planes de estudia de la educación superior del país" (PANAMÁ, 1992).

Esta ley conforme se va describiendo, del artículo 4 al 8 describe lo siguiente:

Artículo 4: Créase lo Comisión de Educación Ambiental para el fomento y orientación de la educación ambiental en el ámbito nacional en la que podrán participar Instituciones gubernamentales y no gubernamentales relacionados con el ambiente. Esta Comisión estará coordinado por el Ministerio de Educación. Artículo 5: Corresponderá a la Comisión de Educación Ambiental, fomentar y fortalecer el conocimiento de la naturaleza, así corno sensibilizar a la población estudiantil y nacional sobra la necesidad de proteger y aprovechar ordenadamente los recursos naturales y la preservación del ambiente. Artículo 6: El Ministerio de Educación promoverá, regulará y supervisará la ejecución de los programas sobre medio ambiente en las escuelas y colegios oficiales y particulares del nivel Inicial, 
medio y superior. Artículo 7: Inclúyase o nivel universitario el contenido y enfoque ambiental como elemento de cultura general obligatorio en todas las carreras que se ofrezcan, con mayor énfasis en aquellos relacionadas con la formación de docentes y comunicadores sociales. Artículo 8: Las Universidades Oficiales supervisaran, en sus áreas de competencia, la Inclusión del temo ambiental en los planes de estudio de los Universidades y Centros de Estudios Superiores Particulares, de acuerdo a lo establecido en el Artículo 95 de la Constitución Política de lo República. (PANAMÁ, 1992).

Los artículos del 4 al 8 es un llamado al establecimiento de la EA por parte del Ministerio de Educación y del Ministerio de Ambiente, como objetivo institucional planteado en el artículo 5, que conlleva el fomentar y fortalecer el conocimiento de la naturaleza. Nuevamente la EA concebida con naturalista y conservacionista, con función de deber en las instituciones del gobierno conjunto a las Universidades de Panamá. Posterior en el Artículo 9 "se establece que los medios de comunicación social deberán promover la formación de una conciencia ambientalista en la opinión público, en base a la función social, que ejercen" (PANAMÁ, 1992). Este artículo es el primer diferencial de EA y su relación a los medios de comunicación, sin embargo, como lo establecido en el artículo promueven una consciencia ambiental a la temática social, descuidando lo político, cultural, entre otras correlaciones donde la EA debe estar presente. Por consciencia ambiental aporta Caporlingua (2010): que es una comprensión del medio ambiente adjunto a un complexo de relaciones entre hombre, naturaleza y sociedad. Es decir que dentro de la EA y la consciencia ambiental no se puede desligar, separar, desunir a la relación del ser humano, la naturaleza y la sociedad.

Panamá, como ya mencionada solo poseen dos leyes de EA, la primera donde se puede observar que por EA, es asociarlo al medio ambiente y la naturaleza, olvidando la relación del ser humano como ser humano, presente en una sociedad con diversas características y mudanzas constantes, campos como el cultural, social, político, entre otras.

En el transcurso del siglo XXI, Panamá aprobó la segunda Ley de EA, la Ley no 38 de 2 de diciembre de 2014, que establece la enseñanza obligatoria de la Educación Ambiental y La Gestión Integral de Riesgo de Desastres, y Dicta Otra Disposición. Rodríguez (2015) destaca que la Ley n @ 38 tiene como objetivo establecer una estrategia para la conservación, protección y desarrollo sostenible. Desarrollo sostenible ligado a una mirada conservacionista y pragmática, término usado en discusión constante a sustentabilidad, sin embargo, en no recaer en una definición de estos términos y si para un fundamento a una EA política y transformadora, que busque el conocer, el entender y el análisis crítico a la crisis socioambiental actual, así como también prevenir los daños ambientales, mediante la comunicación, educación, capacitación e investigación.

En esta Ley no 38 se establece, además, la obligación y responsabilidad del Estado, Ministerio de Educación (Meduca), centros de educación superior, universidades oficiales y medios de comunicación con respecto a la EA la gestión integral de riesgo de desastres; así como también la creación de una comisión para fomentar, fortalecer la EA, orientar y sensibilizar a la población estudiantil sobre el buen aprovechamiento de los recursos naturales, la protección del medio ambiente y la prevención de riesgos. El artículo 1 describe y establece lo siguiente:

Establece la enseñanza obligatoria de la Educación Ambiental y la Gestión Integral de Riesgo de Desastres en el sistema Educativo en el primer, segundo y tercer nivel de enseñanza, 
oficiales y particulares, como eje transversal y una estrategia para la conservación, el desarrollo sostenible de los recursos naturales, la protección del ambiente y la prevención ante eventos adversos, mediante métodos alternativos de comunicación, educación, capacitación e investigación (PANAMÁ, 2014).

En consideración al artículo 1, la EA es planteado como eje transversal y como una estrategia para la conservación, desarrollo sostenible de los recursos naturales y la protección del medio ambiente, es decir que del año de 1992 al 2014. En el transcurrir de 22 años, aun por parte del gobierno panameño, la EA es concebida solo como una perspectiva conservacionista, omitiendo al ser humano en un ambiente político, social, u otras áreas de gran importancia para una mejor sociedad ante las diversas problemáticas y conflictos ambientales que presenta. Del artículo 2 al artículo 4 se establece lo siguiente:

Artículo 2: Se crea la Comisión de Educación Ambiental y de Gestión Integral de Riesgo de Desastres para el fomento y la orientación de la enseñanza de la Educación Ambiental y de Gestión Integral de Riesgo de Desastres, como eje Transversal, a nivel nacional, en la que podrán participar instituciones gubernamentales, no gubernamentales e internacionales relacionadas con el ambiente y la reducción de riesgo de desastres. Esta Comisión estará coordinada por el Ministerio de Educación a través de la Dirección Nacional de Educación Ambiental. Artículo 3: Corresponderá a la Comisión de Educación Ambiental y de Gestión Integral de Riesgo de Desastres apoyar al Ministerio de Educación en el fomento y fortalecimiento del conocimiento sobre la naturaleza, así como sensibilizar a la población estudiantil nacional en la necesidad del aprovechamiento ordenado de los recursos naturales, la protección del ambiente y la prevención para la reducción de riesgo de desastres. Artículo 4: El Ministerio de Educación promoverá, regulará y supervisará la ejecución de los programas de educación ambiental y la gestión integral de riesgo de desastres, como eje transversal, en los centros educativos de educación básica general, educación media y educación superior oficial y particular. (PANAMÁ, 2014).

En estos artículos, se presenta la EA, como responsabilidad de la Dirección Nacional de EA y sus funciones de unir las diversas instituciones gubernamentales y no gubernamentales, la cual busca fortalecer el conocimiento y sensibilización del ciudadano panameño sobre la naturaleza, el aprovechamiento, protección de los recursos naturales y del medio ambiente ante los riesgos de desastres. Posterior en esta legislación se hace un llamado a la Educación Superior de poder contribuir a un contenido con más enfoque ambiental. Tal como se describe en el Artículo 5 que La educación superior incluirá el contenido y enfoque ambiental y la gestión integral de riesgo de desastres, como elementos de cultura general obligatorios en todas las carreras que se impartan, con mayor énfasis en aquellas relacionadas con la formación de docentes y de comunicadores sociales y en las que guarden relación con el ambiente (PANAMÁ, 2014).

En los próximos artículos de esta legislación, va describiendo el artículo 6 y 7, que hace un llamado a que la EA, debe ser prioridad y recaer su obligación en las Universidades oficiales y como eje transversal de parte de los centros educativos del país:

Artículo 6: Las universidades oficiales supervisarán en sus áreas de competencia la inclusión del lema ambiental y la gestión integral de riesgo de desastres en los planes de estudias de las universidades y centros de estudios superiores particulares. Artículo 7: El Estado destinará los recursos económicos necesarios para el desarrollo, el monitoreo y la evaluación de la enseñanza obligatoria de la Educación Ambiental y la Gestión Integral de Riesgo de Desastres, como eje transversal, en los centros educativos oficiales del país. (PANAMÁ, 2014).

Al igual que en la ley 10, el último artículo de la ley 14, hace un llamado a los medios de comunicación y su rol de formar una cultural ambiental con responsabilidad del ciudadano panameño ante los riesgos de 
desastres. Descrito de la siguiente manera, en el artículo 8: "Los medios de comunicación social deberán promover la formación de una cultura ambiental y de gestión integral de riesgo de desastres en la sociedad, con base en la responsabilidad social que ejercen" (PANAMÁ, 2014).

En consideración de ambas leyes, Panamá hace presente y ejecuta diversos programas o proyectos donde la EA es considerada de proteger, de cuidado y de preservación de la naturaleza, recalcando toda la responsabilidad en el Ministerio de Ambiente, Ministerio de Educación y los órganos correspondientes gubernamentales del estado panameño, sin un compromiso consiente y participante de los ciudadanos, reflejado en lo descrito y concebido en las únicas leyes existentes de la EA en Panamá. A partir de este primer análisis, comprendemos como la EA está concebida y dirigida de conservación de la naturaleza y de preservación de los recursos naturales, desde su primer planteamiento en la legislación de 1992 y posterior en la legislación del año 2014.

\section{La educación ambiental crítica como posibilidad de transformación en Panamá}

Panamá, por estar centrado en querer ser un país considerado verde, el medio ambiente y la protección de los recursos naturales renovables, por tratarse de una materia de vida o muerte, es un tema de cartelera en cualquier agenda de Gobierno y que por mucho que se invierta en su cuidado y protección, siempre se verá la carencia y su repercusión en la calidad de vida de todos los ecosistemas (FLORES, 2019). Sin embargo, es necesario tener presente que en una época actual, en una crisis de identidad, en esa relación del ser humano con la naturaleza, destaca Ost (1997):

E que nossa época perdeu, pelo menos depois da modernidade, o sentido do vínculo e o limite das suas relações com a natureza. As duas grandes representações atualmente observáveis desta relação são disso testemunha: a que faz da natureza um objeto e a que, por uma simples alteração de signo, a transforma em sujeito.

La relación ser humano - naturaleza ha pasado por diversas concepciones y modificaciones a lo largo del tiempo, y es importante que países demográficamente pequeños como Panamá, estén anuente a los cambios mundiales que puedan repercutir sobre su sociedad, aun cuando Panamá presente la justificativa de que posee una vida Republicana joven en comparación a otros países.

Panamá tiene muy presente el aspecto político, la consolidación de su soberanía para poder presentar respuestas a sus actuales problemáticas y conflictos ambientales. Sobre todo, por las acciones del ser humano reflejado en el ambiente. Ost (1997), destaca que las acciones del ser humano han estado presente en la crisis socioambiental, es decir aquella relacionada directamente sobre la naturaleza como la deforestación y destrucción sistemática de especies naturales, sin duda, ante todo la crisis de nuestra representación, la crisis de nuestra relación con la naturaleza. Ante tales situaciones, la urgencia de una EA crítica que pueda llevar a la reflexión y transformación del ser humano, entendiendo que el ser humano es un ser individual pero que está presente en lo colectivo, que sus acciones repercuten en los grupal, que tenga presente que como ser humano está en una aventura colectiva, construido identidad en la relación con el otro, con el medio ambiente junto a la naturaleza y la cultura (SAUVÉ, 2013). Por eso la importancia de una 
EA Crítica, por crítica Loureiro (2012), lo define como:

Princípio epistemológico, teórico e metodológico segundo o qual tudo o que existe pode ser racionalmente questionado, negado, afirmado e superado: e as relações sociais são produtos históricos, por tanto, não são imutáveis, podendo ser transformadas pela ação consciente dos agentes sociais. Para a tradição crítica, a possibilidade objetiva de negar algo é condicionado do próprio movimento de mudança das coisas, que se efetiva pela atividade (crítica) de grupos e classes que portam a materialidade superadora dos processos sociais.

La EA en escenarios actuales, en una necesidad de la crítica al sistema hegemónico, predominante de los diversos gobiernos de América Latina, Layrargues (2012) destaca algunas urgencias de esa EA:

EA crítica que no se aleje de su potencial crítico, que se cristalice en el censo común de lo que venga a ser esa práctica educativa, con la concepción de que ella realmente sea importante para la instauración de la cultura de la sustentabilidad, aun cuando, desde el punto de vista crítico.

Actualmente, es necesario partir del entendimiento de EA no solo comprendida como un instrumento de cambio cultural o comportamental, sino también como un instrumento de transformación social para lograr el cambio ambiental (LOUREIRO, 2012). Destacando esta referencia la importancia de la EA crítica donde podríamos incluir otras denominaciones como sinónimo o conceptos similares: Educación Ambiental popular; Educación Ambiental transformadora (LOUREIRO, 2012). Personalmente entendiendo por EA como un proceso donde el ser humano presenta una criticidad a su ambiente y sus diversas interacciones posibles, donde en este documento se resalta el aspecto de una EA política, definida y puesto en práctica "en el sentido que reivindica y prepara a los ciudadanos para exigir justicia social, ciudadanía nacional y planetaria, autogestión y ética en las relaciones sociales y la naturaleza" (REIGOTA, 2006). Por eso primordial, como ciudadano el conocer las estructuras gubernamentales de ambiente y de EA presentes en Panamá, para poder a través de una participación conscientes de las decisiones políticas en temáticas ambientales, más allá de una comprensión de medio ambiente y de EA de perspectiva conservacionista y pragmática. Entendiendo que la perspectiva pragmática, se característica de estar de la mano y derivada de la conservacionista, con similitudes y focos puntuales, con un déficit de ver la amplitud del sistema económico involucrado y el rol del Estado. Perspectiva con objetivo de creciente preocupación de preservación del medio ambiente natural, dependiendo de los recursos presentes y disponibles. Esta perspectiva pragmática es constantemente relacionada al desarrollo, en búsqueda de resultados inmediatos, sin embargo carentes de reflexiones, que es de suma importancia para poder tener una sociedad pensante en la actualidad (LAYRARGUES et al., 2011).

Consciente de que el ser humano presenta características de ser un ser teórico - práctico y la transformación donde las condiciones de vida se dan por la actividad unitaria entre el actuar y pensar (LOUREIRO, 2012). Acciones donde hoy en día al referirse al ser humano, está muy presente la manera de pensar predominantes, donde el modo de vida humano no consigue, al menos en el momento, abandonar la idea de que el medio ambiente es, de alguna forma, servil (OST, 1997). En Panamá, las estructuras de EA y temáticas ambientales en Panamá, en un marco legal y estructural del gobierno panameño, se va dando a través de diversos órganos como una primicia de relacionarla a un orden que pareciese consensuado. 
En partida que al hablar de medio ambiente, es asociarlo en primera instancia a la Ley 41 del 1 de julio de 1998, que es conocida como Ley General de Ambiente, que comprende las reformas aprobadas por la ley 18 de 2003, la ley 44 de 2006, la ley 65 de 2010 y la ley 8 de 2015 donde nos da la primicia de cómo define la palabra ambiente como "Conjunto o sistema de elementos naturales y artificiales de naturaleza física, química, biológica o sociocultural en constante interacción y en permanente modificación por la acción humana o natural, que rige y condicionan la existencia y desarrolla de la vida en sus múltiples manifestaciones" (PANAMÁ, 1998).

En definición aportada por el Ministerio de Ambiente nos da la magnitud de la mirada de ambiente de este Ministerio donde la acción humana y natural está fuertemente relacionado a los diversos acontecimientos que puedan darse, por ende, plantean que su objetivo es:

Establece los principios y normas básicas para la protección, conservación y recuperación del ambiente, promoviendo el uso sostenible de los recursos naturales, a su vez ordena la gestión ambiental y la integra a los objetivos sociales y económicos, a efectos de lograr el desarrollo humano sostenible del país. (PANAMÁ, 1998).

Para el ciudadano panameño, la Ley General del Ambiente, va a establecer un vínculo y su relación a la protección, conservación y recuperación del ambiente a través de uso sostenible, pero carente de criticidad, de transformación, de emancipación del contexto presente.

La EA en Panamá, en aspecto gubernamental está asociada a la Dirección Nacional de Ambiente por parte del Ministerio de Educación y a la En dialogo de que la EA, esta inserido fuertemente al Ministerio de Ambiente, destaca su pragmatismo como cuan inserido esta. La EA también hace presencia en el Ministerio de Educación (MEDUCA), va con la adopción de la constitución de 2 de enero de 1941, sobrevinieron las transformaciones jurídicas y administrativas que permitieron la creación del MEDUCA, la cual introdujo el régimen de los derechos sociales y posterior la creación de la Dirección Nacional de EA, cuyo objetivo es Dirección Nacional de Educación Ambiental:

Concienciar a la comunidad educativa de la importancia de su participación en la protección, preservación y aprovechamiento ordenado de los recursos naturales, mediante la Educación Ambiental dirigida a lograr un cambio de actitud y valores, a fin de sensibilizarla, en la preservación del equilibrio que debe existir entre el hombre y la naturaleza, para mejorar la calidad del ambiente y por ende, la calidad de vida. (MEDUCA, 2019).

En cuanto al Ministerio de Ambiente, el departamento de EA, se da en el Decreto Ejecutivo $\mathrm{N}^{\circ} 36$, el departamento de EA, esta inserido dentro de la Dirección de Cultura Ambiental, cuyo objetivo es:

Objetivo Fomentar la cultura y la educación ambiental, a través de la formación integral, investigación, promoción y divulgación, de la relación armónica entre el medio natural y las actividades antropogénicas, que impulsen un desarrollo sostenible, contribuyendo a cimentar los valores ambientales en la sociedad. (PANAMÁ, 2018).

De parte del departamento de EA, el objetivo es contribuir con el desarrollo de la cultura y los valores ambientales y la trasformación de la conducta de la población, a través de la Educación Ambiental No Formal e Informal, la cual presenta las siguientes funciones:

Elaborar y actualizar el Plan Nacional de Educación Ambiental No Formal e Informal. Optimizar el Centro de Documentación del Ministerio de Ambiente, para un servicio eficiente a los usuarios. Formular e implementar con actores claves, planes y programas de educación ambiental. Apoyar a Instituciones del Sector Público y Organizaciones No Gubernamentales, en el desarrollo de las acciones del Plan Nacional de Educación 
Ambiental No Formal e Informal. Apoyar las acciones para la ejecución de las campañas de concienciación dirigidas a la conservación del ambiente, con los diferentes actores claves involucrados en la educación ambiental. Apoyar la ejecución de Convenios con Organismos Gubernamentales, no Gubernamentales y Organizaciones de Base Comunitarias relacionados con la educación ambiental. Ejecutar programas y actividades de Educación Ambiental No Formal e Informal, para la capacitación de funcionarios públicos y miembros de la sociedad civil con enfoque de género, según lineamientos establecidos. (PANAMÁ, 2018).

Entre las palabras más mencionadas en el marco legal, está presente conservar, concienciar y participación de la sociedad panameña, vemos que en ningún momento se presenta el llamado a un contexto social, cultural, político, para un entendimiento del papel del ser humano, que sus acciones han proporcionado los acontecimientos y momentos que estamos viviendo en nuestra actualidad. Redactados y reflejados en documentos de EA como guías didácticas en la educación primaria, realizado por parte del Ministerio de Educación y del Ministerio de Ambiente, y en las mencionadas leyes de EA.

En un análisis de las dos legislaciones y ver como la EA esta inserido en el Ministerio de Ambiente y el Ministerio de Educación a través de Direcciones Nacionales de Educación Ambiental, donde predomina las perspectivas conservacionistas y en un pragmatismo de cuidar los recursos naturales y la protección de medio ambiente.

Es un punto de partida a una criticidad anuente a un cambio de mentalidad de que el ser humano está más que relacionado solo al medio ambiente, está muy de la mano con sus características éticas, políticas, sociales, entre otras. Para poder llegar a un consenso de convivencia garantizando un mejor medio ambiente para esta y futura generación. Pero, si destacamos a nivel mundial las vertientes de desastres, catástrofes y conflictos ambientales.

Un llamado a las dos legislaciones y al gobierno panameño a tener más presente que la EA, más que conservacionista y pragmática debe tener al ciudadano y a la sociedad panameña en constante formación de una sociedad consciente en todos los espacios de interacción del ser humano. La República de Panamá consolidándose como una economía potente, sin embargo, con facilidad de asociar su perspectiva de medio ambiente al utilitarismo, de la cual Acselrad (2002)

Para a razão utilitária hegemônica, o meio ambiente é uno e composto estritamente de recursos materiais, sem conteúdos sócio-culturais específicos e diferenciados; é expresso em quantidades; justifica interrogações sobre os meios e não sobre os fins para os quais a sociedade se apropria dos recursos do planeta; pressupõe um risco ambiental único, instrumental.

Por consiguiente, es necesario a aprender a utilizar responsablemente los recursos de nuestra casa de vida común, a compartir todo solidariamente (SAUVÉ, 2016). En tiempos actuales, una sociedad panameña que tenga presente que la EA va más allá de una relación con la naturaleza, por eso un llamado a una reflexión y una criticidad, conociendo de base una EA transformadora y no una confusa en escenarios tan importantes para el ser humano, Layrargues (2012) aporta:

E se, para os atores sociais da Educação Ambiental, a Educação Ambiental ficou confusa com tantas novas adjetivações; para a sociedade, a Educação Ambiental aparece como uma práxis unidimensional, indistinta, que tem como função óbvia a criação da "consciência ecológica nas pessoas", seja por meio do encantamento com a natureza, seja por meio das mudanças de comportamentos individuais diante do consumo e da geração de resíduos.

En constantes cambios es necesario una sociedad que tenga presente los acontecimientos que 
envuelven su entorno y un llamado a una EA transformadora que ocupe los espacios presentes en una sociedad en crisis, que se refleja en el ambiente.

\section{CONCLUSIONES}

Panamá, uno de los países latinoamericanos de mayor crecimiento económico, es un país anuente a la búsqueda constante de ser un país verde, sin embargo, en profunda ligación a una EA conservacionista. De la cual deriva su legislación que toma como base el conservacionismo, el naturalismo y la protección de sus recursos naturales.

Hablar de una EA crítica, hoy en día, es un llamado a la sociedad a ser más conscientes y participantes, conociendo el contexto social, político, cultural que han hecho énfasis en sus respectivas legislaciones y su marco legal, que conlleva a la practica en los diversos órganos gubernamentales de un país. En Panamá, recayendo ese deber en el Ministerio de Ambiente y el Ministerio de Educación, pero careciendo del ciudadano panameño, como agente de cambio ante las situaciones, problemáticas y conflictos ambientales que rigen o están presentes en una sociedad en constante cambio. Por eso un llamado más a conocer y dar lineamiento a una sociedad con una ética activa y en la cual este presente el reconocimiento del ser humano dentro de un ambiente determinado, debido a que en sus acciones y su toma de decisiones implica el venir y cuidado de las futuras generaciones.

Panamá tiene su origen en temáticas ambientales por los años de 1970 y principalmente relacionado a las luchas constantes del pueblo panameño contra el gobierno estadounidense por la recuperación del canal y su soberanía nacional. Sin embargo, es en este siglo XX donde Panamá comenzó a fundamentarse más en los pequeños pasos de búsqueda de un medio ambiente más saludable y de preservación de sus recursos naturales. Derivando en la creación de áreas protegidas, como parques y refugios de vida, leyes para el ambiente y a establecer agencias de conservación.

Actualmente, al hablar de Panamá, es asociarlo al Canal de Panamá, que en una mirada nacional e internacional es el aporte económico al país, donde se aprovecha su privilegiada posición geográfica y otros factores (turismo, sector bancario), que lo ha convertido en una meca para el negocio y las actividades comerciales. Sin embargo, todo esto viene con un costo para el medio ambiente, para la industria, ya sea en la forma de turismo o de operaciones mineras, que causan gran pérdida a la naturaleza, hoy visto reflejado en dos grandes sectores que ha conllevado a una preocupación ambiental de parte de la sociedad panameña: la deforestación y los recursos hídricos del país.

Panamá, en una mirada hacia los próximos años, en respecto a una EA crítica, es necesario poder posicionarse y dar respuestas a los diversos conflictos ambientales presentes en los últimos años, que son constantemente comentados por los diversos medios de comunicación. Entre ellos se destacan la extracción de minerales, construcción de hidroeléctricas y tala de bosques sin los permisos respectivos. De estas problemáticas y conflictos ambientales que va en constante aumento y crecimiento a nivel nacional e internacional, es un llamado a conocer la actualidad de la EA y su concepción de parte del gobierno y de la sociedad panameña, para garantir un mejor país, un mejor desarrollo y sobretodo el bienestar de las futuras 
generaciones.

\section{REFERENCIAS}

ACSELRAD, H.. Justiça Ambiental. In: FERRARO JÚNIOR, L. A.. Encontros e Caminhos: formação de educadoras(es) ambientais e coletivos educadores. Brasília: MMA, 2005.

CAPORLINGUA, V. H.. O revelar da consciência ambiental na sentença judicial transformadora como forma de efetividade processual. Tese (Doutorado em Educação Ambiental) - Universidade Federal do Rio Grande, Rio Grande, 2010.

DIAS, F. G.. Educação Ambiental: Princípios e Práticas. 3 ed. São Paulo: Gaia, 1992.

DIAZ-PINZÓN, F.. El movimiento ambiental panameño frente al neoliberalismo: estudio de caso Cerro Colorado contra la minería a cielo abierto, referenciado a la región centroamericana, año 1989 - 2010. Disertación (Maestría) Facultad Latinoamericana de Ciencias Sociales, San José, 2013.

FLORES, N.. Conflictos ambientales, cómo mediar para consensuar 2020. Cidade do Panamá, 2019.

FRANCO, D.. El reto de la ministra de Educación 2015. Cidade do Panamá, 2019.

FREIRE, P.. Pedagogia do oprimido. Rio de Janeiro: Paz e Terra, 1987

GRÜN, M.. Ética e Educação Ambiental: a Conexão Necessária. Campinas: Papirus, 2006.

LAYRARGUES, P. P.. Para onde vai a Educação Ambiental? O cenário político-ideológico da Educação Ambiental brasileira e os desafios de uma agenda política crítica contrahegemônica. Revista Contemporânea de Educação, n.14, 2012.

LAYRARGUES, P. P.; LIMA, G. F. C.. As macrotendências político pedagógicas da Educação Ambiental brasileira. Ambiente \& Sociedade, São Paulo v.17, n.1, p.23-40, 2014.

PANAMÁ. LA PRENSA: La Constitución 41 años después. Cidade do Panamá, 2019.

LOUREIRO, C. F. B.. Sustentabilidade e educação: um olhar da ecologia política. São Paulo: Cortez, 2012.

LOUREIRO, C. F. B.. Trajetória e fundamentos da educação ambiental. São Paulo: Cortez, 2012.
OST, F.. A natureza à margem da lei: a ecologia à prova do Direito. Lisboa: Instituto Piaget, 1997.

ONU. Organização das Nações Unidas. Declaração da Conferência das Nações Unidas sobre o Meio Ambiente Humano. ONU, 1972.

ONU. Organização das Nações Unidas. Conferência das nações unidas sobre meio ambiente e desenvolvimento Rio/92. Tratado de educação ambiental para sociedades sustentáveis e responsabilidade global. ONU, 1992.

PANAMÁ. Comisión de Población Ambiente y Desarrollo CDPAD. Cidade do Panamá, 2017.

PANAMÁ. Ley n. 10, de 24 de junio de 1992. Ley de Educación Ambiental en Panamá. Cidade do Panamá, 1992.

PANAMÁ. Ley n. 41 de 1 de julio de 1998. Ley General de Ambiente de la República de Panamá. Panamá, 1998.

PANAMÁ. Ley n. 38, de 02 de diciembre de 2014. Cidade do Panamá, 2014.

PANAMÁ. Ministerio de Educación. Información general 2019. Cidade do Panamá, 2019.

REIGOTA, M.. O que é educação ambiental? São Paulo: Brasiliense, 2006.

RODRIGUEZ, M.. La educación ambiental ya es ley de la República 2015. La Estrella, 2015.

SATO, M.. Apaixonadamente Pesquisadora em Educação Ambiental. Revista Educação, Rio Claro, v.9, n.16, p.24-35, 2001.

SAUVÉ, L.. Viver juntos em nossa Terra: desafios contemporâneos da educação ambiental. Revista Contrapontos, Itajaí, v.16, n.2, p.288-299, 2016.

TIBLISI. Conferência Intergovernamental sobre Educação Ambiental aos Países Membros. CEI de 14 a 26 de outubro de 1977. TIBLISI, 1977.

VASCONCELOS, L. S.. O meio ambiente ecologicamente equilibrado como direito e dever fundamental na constituição federal do Brasil de 1988. Revista Jurídica da FA7, Fortaleza, v.9, n.1, p.97-108, 2012.

A CBPC - Companhia Brasileira de Produção Científica (CNPJ: 11.221.422/0001-03) detém os direitos materiais desta publicação. Os direitos referem-se à publicação do trabalho em qualquer parte do mundo, incluindo os direitos às renovações, expansões e disseminações da contribuição, bem como outros direitos subsidiários. Todos os trabalhos publicados eletronicamente poderão posteriormente ser publicados em coletâneas impressas sob coordenação da Sustenere Publishing, da Companhia Brasileira de Produção Científica e seus parceiros autorizados. Os (as) autores (as) preservam os direitos autorais, mas não têm permissão para a publicação da contribuição em outro meio, impresso ou digital, em português ou em tradução. 